\title{
The Influences of Tai Chi on Balance Function and Exercise Capacity among Stroke Patients: A Meta-Analysis
}

\author{
Xinhu Zheng $\left(\mathbb{D},{ }^{1}\right.$ Xiaoyang Wu, ${ }^{2}$ Zuhong Liu, ${ }^{1}$ Jing Wang, ${ }^{3}$ Keyang Wang, ${ }^{4}$ Jilin Yin, ${ }^{5}$ \\ and Xing Wang $\mathbb{B}^{1}$ \\ ${ }^{1}$ Shanghai University of Sport, Shanghai 200438, China \\ ${ }^{2}$ Jiaxing University, Jiaxing 314001, China \\ ${ }^{3}$ Shanghai Lixin University of Accounting and Finance, Shanghai 201620, China \\ ${ }^{4}$ Shanghai University of Political Science and Law, Shanghai 201207, China \\ ${ }^{5}$ Bei Gulf University, Qinzhou 535011, China \\ Correspondence should be addressed to Xing Wang; 18930132117@163.com
}

Received 16 October 2020; Revised 31 January 2021; Accepted 11 February 2021; Published 25 February 2021

Academic Editor: Jiao Liu

Copyright ( 2021 Xinhu Zheng et al. This is an open access article distributed under the Creative Commons Attribution License, which permits unrestricted use, distribution, and reproduction in any medium, provided the original work is properly cited.

\begin{abstract}
Objective. This study aims to explore the influences of Tai Chi on the balance function and exercise capacity among stroke patients. Methods. Databases including PubMed, Embase, WOS (Web of Science), the Cochrane Library, CNKI (China National Knowledge Infrastructure), Wanfang Data, VIP (VIP database), and CBM (China Biology Medicine disc) were retrieved to gather the figures of randomized controlled trials on the balance function and exercise capacity among stroke patients. Then relevant data were input and analyzed in Review Manager 5.3. Results. Nineteen papers were included and analyzed in this study. According to the combined effect size, the balance function of stroke patients improved significantly: the Berg Balance Function Scale score $[\mathrm{MD}=7.67,95 \% \mathrm{CI}(3.44,11.90)]$; standing and walking test scores $[\mathrm{MD}=3.42,95 \% \mathrm{CI}$ $(4.22,-2.63)]$; gravity swing area $[\mathrm{MD}=0.79,95 \% \mathrm{CI}(1.48,0.10)]$; and gravity swing speed $[\mathrm{MD}=-5.43,95 \% \mathrm{CI}(-7.79,3.08)]$. In addition, the exercise capacity improved significantly as well: the FMA (Fugl-Meyer Assessment Scale) scale score $[\mathrm{MD}=4.15,95 \%$ CI $(1.68,6.63)]$. There are no significant influences or changes of other related results. Conclusions. Stroke patients are able to improve their balance functions and exercise capacities prominently when they do Tai Chi exercise once or twice a week and $\geq 5$ times/week and $>30 \leq 60 \mathrm{~min} /$ time.
\end{abstract}

\section{Introduction}

Stroke, a common and frequently occurring disease among middle-aged and elderly people, is a disease of brain tissue damage caused by the sudden rupture of cerebral blood vessels or vascular obstruction, which has high incidence, high disability rate, and high mortality rate [1]. Hemiplegia is one of the most common sequelae of stroke, whose patients usually lose muscle strength and balance function of one limb, making them inconvenient or unable to move at all [2]. According to statistics, there are about two million new stroke patients every year in China; nowadays, there are a total of 6-7 million survival Chinese patients, whose mortality rate reaches $10 \%-30 \%$ and the disability rate is around
$60 \%-70 \%$. In addition, around $80 \%$ of stroke patients suffer from impairment of lower limb motor function [3], which severely troubles their daily activities and lowers their quality of life [4].

As a low-intensity aerobic exercise, Tai Chi is a safe, effective, and inexpensive adjuvant therapy and rehabilitation method [5] and has been reported many times in recent years for being applied in daily rehabilitation of patients with chronic diseases and the elderly [6]. The evidence of quantitative research shows that Tai Chi can relax the tense muscles of patients, enhance their flexibility and strength, inhibit the occurrence of abnormal postures and spasms, improve the balance function, enhance the normal exercise ability and control ability of stroke patients, and have many 
positive effects on the daily activities and psychological emotions of stroke patients $[7,8]$, thus improving the life quality of stroke patients.

In previous studies, none of the randomized controlled trial studies on Tai Chi intervention have been integrated to analyze the role of Tai Chi on stroke. Therefore, this study aims to clarify the effect of Tai Chi on the balance function and exercise ability among stroke patients, as well as illustrate the influences of various exercise variables among the patients, so as to provide references for the development of precise exercise programs.

\section{Research Method}

This study followed the requirements of the international meta-analysis writing guidelines (the PRISMA statement for reporting systematic reviews and meta-analyses of studies that evaluate health-care interventions: explanation and elaboration) [9] for the selection and use of research methods. The protocol for this study was registered with INPLASY (202110086).

\subsection{Literature Inclusion and Exclusion Criteria}

2.1.1. Research Design. A meta-analysis of randomized controlled trials (RCT) and the influences of Tai Chi on balance function and exercise capacity among stroke patients is conducted.

2.1.2. Criteria of the Included Literature. (1) The subjects of the study were all stroke patients with stable conditions and were in line with the stroke diagnostic criteria formulated by the 4th Cerebrovascular Disease Academic Conference of the Chinese Medical Association [10] or the stroke diagnostic criteria regulated by the American Heart Association/ American Stroke Association (AHA/ASA) [11]; (2) the vital signs were stable; (3) if a study had two treatment groups, it was regarded as two studies; and (4) the type of this study is randomized controlled trial (RCT).

2.1.3. Criteria of the Excluded Literature. (1) The subjects included in the experiment were normal elderly without stroke diseases; (2) the subjects had dyskinesias and could not complete Tai Chi exercises; (3) there was no pure Tai Chi exercise intervention group; (4) papers with multiple releases and low-quality assessment; and (5) papers with unclear and incalculable experimental data.

2.2. Literature Retrieval Strategy. Databases including PubMed, the Cochrane Library, Embase, Web of Science (WOS), China National Knowledge Infrastructure (CNKI), Wanfang Data, VIP, and China Biology Medicine disc (CBM) were retrieved to gather randomized controlled trial figures on balance function and exercise mobility on stroke patients who did Tai Chi exercise. The retrieval period started from the initial period of each database to June 30, 2020. The search strategy was based on the principle of
PICOS (Population, Intervention, Comparison, Outcomes, and Study design) and adopted a combination of subject words and free words, which were determined after repeated prechecks, supplemented by manual search and the references tracking of those papers when necessary. Chinese search terms include cerebral stroke (脑卒中), stroke (中 风), cerebral thrombosis (脑血栓), cerebral infarction (脑梗 死), Tai Chi (太极), Tai Chi Chuan (太极拳), random (随 机), and experiment (试验). The English search terms used the Web of Science database as an example:

\#1 TS = (stroke or apoplexy or cerebrovascular accident)

\#2 TS = (Tai Ji or Tai-ji or Tai Chi or Tai Ji Quan or Taiji or Taijiquan or Tai Chi Chuan)

\#3 TS = (balance or equilibrium or posture control or posture reaction or athletic ability or exercise performance or motor ability or exercise capacity or sports ability)

\#4 TS = (randomized controlled trial or randomized or controlled or trial)

$\# 5 \# 1$ and \#2 and \#3 and \#4

2.2.1. Intervention Measures. At least, one group only used Tai Chi exercise as the intervention method, and the control group received placebo, health education, daily activities, routine nursing, etc.

2.2.2. Outcome Indicators. Outcome indicators selected various scales and testing indicators for evaluating balance function and exercise ability, including the Berg Balance Scale (BBS), standing and walking, gravity center swing, short physical performance battery (SPPB), Fugl-Meyer Assessment Scale (FMA), and six-minute walking test (6MWT).

\subsection{Literature Screening, Data Extraction, and Quality Evaluation}

2.3.1. Literature Screening. Two researchers used independent double-blind methods to screen the literature based on the criteria of the included and excluded literature and extracted relevant data. If there was a disagreement on the mutual review, screening, and data extraction phases, a third researcher would join in to discuss whether to include the data.

2.3.2. Data Extraction. The data extracted from the literature mainly include the author's name, year of publication, nationality, sample size, age, exercise form, exercise cycle, exercise duration, exercise frequency, and exercise intensity. The outcome indicator data extracted from the study were the change values of outcome index included in the literature, that is, the postintervention test data subtracted the preintervention test data. 
Physical exercise variables were divided based on relevant previous researches: exercise duration lasting for $\leq 30 \mathrm{~min}$ (minutes), $>30 \leq 60 \mathrm{~min}$, and $>60 \mathrm{~min}$ [12]; exercise intensity had low, medium, and high categories [13]; exercise frequency included 1-2 times/wk (times per week), 3-4 times/wk, and $\geq 5$ times/wk, and the cycle was divided into $\leq 12$ weeks, $>12 \leq 24$ weeks, and $>24$ weeks [14].

2.3.3. Quality Evaluation. The risk of bias criteria of randomized controlled trials (RCT) in the Cochrane Collaborative Network were adopted to perform qualitative evaluation of seven aspects of RCT: random sequence generation, distribution concealment, blind method of subjects and researchers, blind method of outcome evaluator, incomplete outcome data, selective report, and other bias, and each index was judged by "low bias risk," "uncertain bias risk," or "high bias risk."

2.3.4. Level of Evidence. In this study, the evidence level of the included literature was graded according to the evidence level of the Oxford Center for Evidence-Based Medicine [15] (Table 1).

2.3.5. Statistical Analysis. Using Review Manager 5.3 for the literature data process, this paper had the combined effect size and heterogeneity test and drew a forest diagram. The literature outcome indicators were all continuous variables, the effect size chose Mean Difference (MD) and Standardized Mean Difference (SMD), and the effect size was $\mathrm{MD}=95 \%$ of confidence interval. This meta-analysis strictly follows the PRISMA guidelines [8] and used the $P$ value and I2 for the heterogeneity test. If there was no statistical heterogeneity between the results of each study (I $\leq 50 \%$, $P>0.10)$, the fixed-effects model would be selected. If there was statistical heterogeneity between the studies, the source of the heterogeneity would be further analyzed, and the random effects model was used for analyses after excluding the influence of obvious clinical heterogeneity.

\section{Results}

3.1. Process and Results of Literature Screening. Initially, a total of 380 articles were retrieved from the database, among which 41 repeated papers were excluded. According to the inclusion and exclusion criteria, 303 papers were screened and excluded. Then, 17 articles were excluded after a full-text screening. At last, 19 articles were left (Figure 1).

\subsection{The Included Literature}

3.2.1. Basic Information of the Included Literature. Nineteen randomized controlled trial (RCT) literature were included, whose subjects were all stroke patients. According to the evidence level standard and recommendation level of the Oxford Center for Evidence-Based Medicine, the evidence levels of the included literature were all $\mathrm{Ib}$, which stands for a relatively high evidence level and good quality (Table 2).
3.2.2. Sports Intervention Features in the Included Literature. Tai Chi, as an intervention method, was adopted in all the 19 included papers. Their selected intervention period lasted 12 weeks or less, and there were two articles that did not report the intervention period. Four papers chose the intervention frequency as twice a week, six papers chose 3-4 times/wk, and nine papers chose $\geq 5$ times/wk. Four papers had the exercise duration $\leq 30 \mathrm{~min}$ per time, 14 papers had 30-60 min per time, and one paper had >60 min per time. The research results in the included literature were all the balance function and exercise ability among stroke patients (Table 3).

3.2.3. Bias Risk Analysis of the Included Literature. As shown in Figures 2 and 3, Review Manager software was used to analyze the risk of bias in the included literature. Among these papers, 5 papers did not explain the method of random allocation of subjects, and only 4 papers used the method of allocation and hiding to randomly divide the subjects and did not blind the subjects. Only 3 papers blinded the subjects and 6 papers conducted the blinding of evaluation, among which 2 papers conducted double-blinded experiments on both subjects and result evaluation. Data of the 19 papers were complete, and other sources of bias risk were not explained.

\subsection{Meta-Analysis Results}

3.3.1. The Influences of Tai Chi on the Berg Balance Scale. Six papers studied the influence of Tai Chi on Berg Scale scores. The heterogeneity analysis showed that $I^{2}=99 \%$, $P<0.01$, showing heterogeneity features in those studies. Therefore, the random effects model was used to analyze the results, and the combined effect size showed $[\mathrm{MD}=7.67$, $95 \%$ CI $(3.44,11.90)]$. Compared with the control group, Tai Chi can significantly improve the Berg Balance Scale score of stroke patients (Figure 4).

3.3.2. The Influences of Tai Chi on the Standing and Walking Test. Three papers studied the influence of Tai Chi on the standing and walking test of stroke patients. The analysis of heterogeneity showed that $I^{2}=13 \%, P=0.32>0.05$. In other words, there was no statistical heterogeneity between those studies. Thus, the fixed-effects model was selected to analyze, and the meta-analysis results were $[\mathrm{MD}=-3.42,95 \% \mathrm{CI}$ $(-4.22,-2.63)]$, indicating that Tai Chi can significantly improve the standing and walking ability of stroke patients (Figure 5).

3.3.3. The Influence of the $6 \mathrm{~m}$ Walking Test on the Patients Doing Tai Chi. Two papers studied the influences of Tai Chi on the $6 \mathrm{~m}$ walking experiment. The heterogeneity results showed that $I^{2}=89 \%, P=0.003<0.05$, so the random effects model was selected to conduct metaanalysis of the results, and the results showed that the combined effect size was $[\mathrm{MD}=30.94,95 \%$ CI $(-11.34$, 73.23)]. Tai Chi can significantly improve the $6 \mathrm{~m}$ walking 
TABLE 1: Evidence level and recommendations grades of the Oxford Center for Evidence-Based Medicine.

\begin{tabular}{lcc}
\hline Level of evidence & Contents & Recommended hierarchy \\
\hline $\mathrm{Ia}$ & Systematic review with homogeneity of RCTs & I \\
$\mathrm{Ib}$ & Individual RCTs (with narrow confidence interval) & Systematic reviews with homogeneity of cohort studies \\
$\mathrm{IIa}$ & Individual cohort study (including low-quality RCTs, e.g., $<80 \%$ follow-up) & Outcomes research \\
$\mathrm{IIb}$ & Systematic review of homogeneous case-control studies & III \\
$\mathrm{IIc}$ & Individual case-control study & IV \\
$\mathrm{IIIb}$ & Case series (and poor-quality cohort and case-control studies) & V \\
\hline III & Expert opinions without explicit critical appraisal & \\
\hline
\end{tabular}

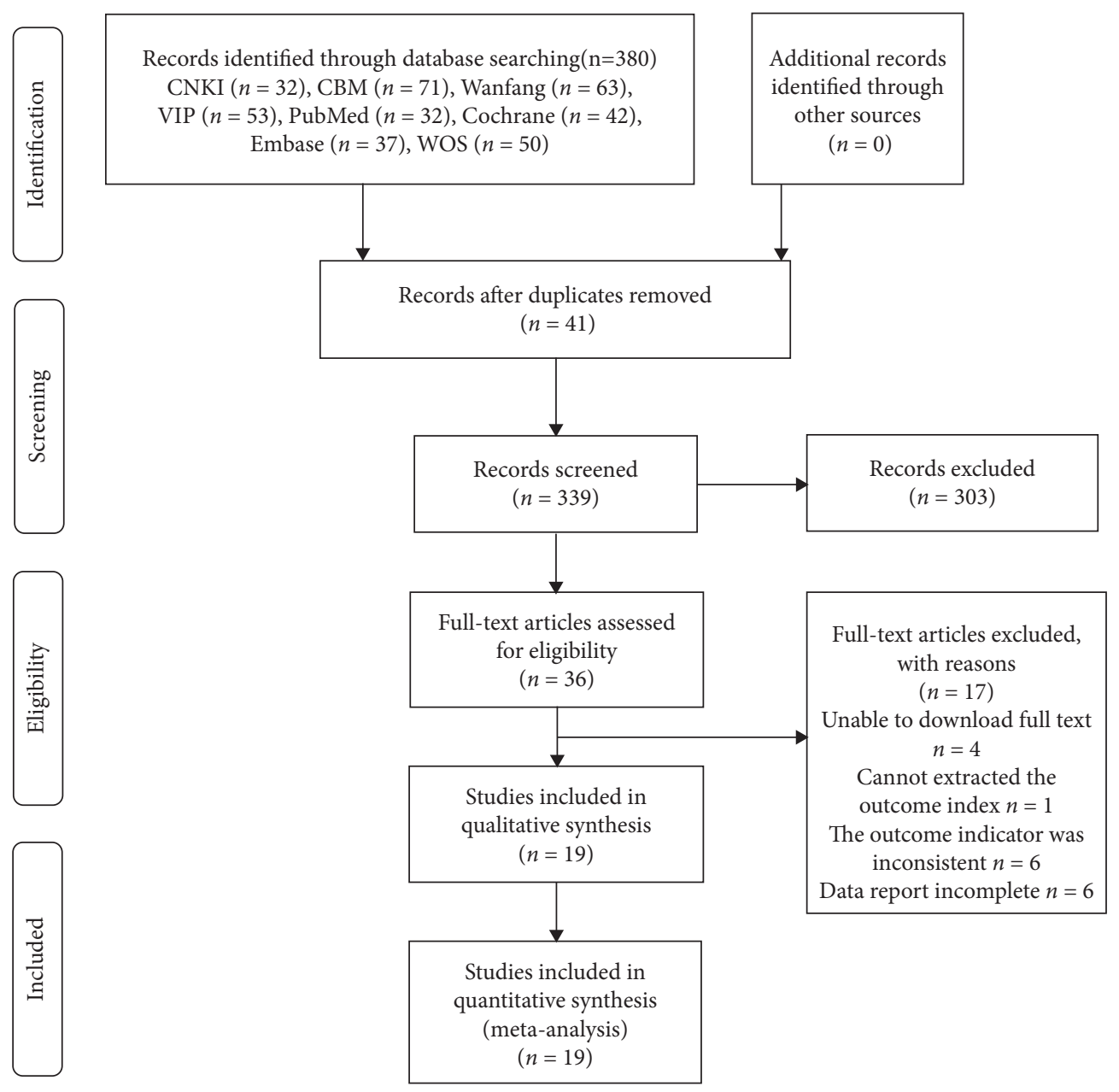

FIGURE 1: Literature screening process.

distance of stroke patients, but the difference is not significant (Figure 6).

\subsubsection{The Influence of Tai Chi on the Swing of the Gravity} Center. Two papers studied the influence of Tai Chi on the swing area of the center of gravity (Figure 7), three papers studied the effect of Tai Chi on the swing length of the center of gravity (Figure 8), and two papers studied the effect of Tai Chi on the swing speed of the center of gravity (Figure 9). The heterogeneity test results were $I^{2}=83 \%, P=0.02<0.05$;
$I^{2}=97 \%, P=<0.01$; and $I^{2}=0 \%, P=0.65>0.05$. Therefore, the random effect model was selected in the tests of swing area of gravity center and swing length of gravity center, and the fixed-effects model was selected in the swing speed of the gravity center test to conduct meta-analysis on the results. The swing area of gravity center was $[\mathrm{MD}=-0.79,95 \% \mathrm{CI}$ $(-1.48,-0.10)]$, swing length of gravity center was $[\mathrm{MD}=-0.28,95 \% \mathrm{CI}(-2.05,1.49)]$, and swing speed of gravity center was $[\mathrm{MD}=-5.43,95 \% \mathrm{CI}(-7.79,-3.08)]$. The results show that Tai Chi can significantly improve the area and speed of the gravity center swing of stroke patients while 
TABLE 2: Basic information of the included literature.

\begin{tabular}{|c|c|c|c|c|c|c|c|}
\hline No. & Included literature & Nationality & Symptom & $\begin{array}{l}\text { Number of subjects } \\
(\mathrm{T} / \mathrm{C})\end{array}$ & Age $(\mathrm{T} / \mathrm{C})$ & $\begin{array}{l}\text { Percentage of men (T/C) } \\
(\%)\end{array}$ & Level of evidence \\
\hline 1 & Au-Yeung et al. [16] & China & Stroke & $59 / 55$ & $\begin{array}{l}61.7 \pm 10.5 \\
65.9 \pm 10.7 \\
\end{array}$ & $\begin{array}{r}55.93 \\
60.00 \\
\end{array}$ & $\mathrm{Ib}$ \\
\hline 2 & Chan and Tsang [17] & China & Stroke & $9 / 9$ & $\begin{array}{l}63.9 \pm 6.1 \\
63.2 \pm 6.0\end{array}$ & $\begin{array}{l}55.56 \\
44.44\end{array}$ & $\mathrm{Ib}$ \\
\hline 3 & Huang et al. [18] & China & Stroke & $14 / 14$ & $\begin{array}{l}62.21 \pm 9.74 \\
59.93 \pm 9.96\end{array}$ & $\begin{array}{l}85.71 \\
71.43 \\
\end{array}$ & $\mathrm{Ib}$ \\
\hline 4 & Kim et al. [19] & Korea & Stroke & $11 / 11$ & $\begin{array}{l}53.45 \pm 11.54 \\
55.18 \pm 10.20\end{array}$ & $\begin{array}{l}63.60 \\
54.50\end{array}$ & $\mathrm{Ib}$ \\
\hline 5 & $\begin{array}{l}\text { Taylor-Piliae and Coull } \\
{[20]}\end{array}$ & The U.S. & Stroke & $16 / 12$ & $\begin{array}{l}72.8 \pm 10.1 \\
64.5 \pm 10.9\end{array}$ & $\begin{array}{c}62.5 \\
58.33 \\
\end{array}$ & $\mathrm{Ib}$ \\
\hline 6 & Taylor-Piliae et al. [21] & The U.S. & Stroke & $53 / 48$ & $\begin{array}{l}71.5 \pm 10.3 \\
68.2 \pm 10.3 \\
\end{array}$ & $\begin{array}{l}64.2 \\
47.9 \\
\end{array}$ & $\mathrm{Ib}$ \\
\hline 7 & Zheng et al. [22] & China & Stroke & $85 / 85$ & $\begin{array}{l}61.01 \pm 5.20 \\
60.73 \pm 6.05\end{array}$ & $\begin{array}{l}32.9 \\
28.2\end{array}$ & $\mathrm{Ib}$ \\
\hline 8 & Fan et al. [23] & China & Stroke & $43 / 43$ & $\begin{array}{l}63.4 \pm 5.0 \\
63.8 \pm 5.3 \\
\end{array}$ & $\begin{array}{l}67.44 \\
69.77 \\
\end{array}$ & $\mathrm{Ib}$ \\
\hline 9 & Fu and Zhang [24] & China & Stroke & $30 / 30$ & $\begin{array}{l}59.7 \pm 7.6 \\
60.3 \pm 8.4\end{array}$ & $\begin{array}{c}63.33 \\
60 \\
\end{array}$ & $\mathrm{Ib}$ \\
\hline 10 & Li et al. [25] & China & Stroke & $30 / 30$ & $\begin{array}{l}71.03 \pm 8.21 \\
71.06 \pm 8.33\end{array}$ & $\begin{array}{l}56.67 \\
53.33\end{array}$ & $\mathrm{Ib}$ \\
\hline 11 & Liu et al. [26] & China & Stroke & $24 / 24$ & $\begin{array}{l}52.13 \pm 14.13 \\
53.51 \pm 12.63 \\
\end{array}$ & $\begin{array}{l}58.33 \\
45.83\end{array}$ & $\mathrm{Ib}$ \\
\hline 12 & Xiao [27] & China & Stroke & $46 / 46$ & $\begin{array}{l}57.51 \pm 1.14 \\
57.68 \pm 1.75\end{array}$ & $\begin{array}{l}67.39 \\
65.22 \\
\end{array}$ & $\mathrm{Ib}$ \\
\hline 13 & $\mathrm{Xu}$ et al. [28] & China & Stroke & $40 / 40$ & $\begin{array}{l}60.14 \pm 10.25 \\
48.23 \pm 12.32 \\
\end{array}$ & $\begin{array}{l}55 \\
40 \\
\end{array}$ & $\mathrm{Ib}$ \\
\hline 14 & Yang and Liu [29] & China & Stroke & $28 / 21$ & $\begin{array}{l}51.43 \pm 47.63 \\
54.02 \pm 38.41\end{array}$ & $\begin{array}{l}60.71 \\
61.90 \\
\end{array}$ & $\mathrm{Ib}$ \\
\hline 15 & Yang and Tang [30] & China & Stroke & $28 / 21$ & $\begin{array}{l}51.43 \pm 15.63 \\
54.85 \pm 11.85\end{array}$ & $\begin{array}{l}60.71 \\
66.67\end{array}$ & $\mathrm{Ib}$ \\
\hline 16 & Yang et al. [31] & China & Stroke & $30 / 30$ & $\begin{array}{c}58 \pm 11.27 \\
60.07 \pm 7.87\end{array}$ & $\begin{array}{c}66.67 \\
60 \\
\end{array}$ & $\mathrm{Ib}$ \\
\hline 17 & Zhang et al. [32] & China & Stroke & $20 / 20$ & $\begin{array}{l}67.80 \pm 12.22 \\
66.65 \pm 10.49\end{array}$ & $\begin{array}{l}50 \\
55\end{array}$ & $\mathrm{Ib}$ \\
\hline 18 & Zhao et al. [33] & China & Stroke & $30 / 30$ & $\begin{array}{l}53.85 \pm 11.69 \\
51.38 \pm 14.83\end{array}$ & $\begin{array}{l}66.67 \\
63.33 \\
\end{array}$ & $\mathrm{Ib}$ \\
\hline 19 & Yi et al. [34] & China & Stroke & $66 / 66$ & $\begin{array}{l}48.78 \pm 13.52 \\
47.69 \pm 14.91\end{array}$ & $\begin{array}{l}63.64 \\
59.09 \\
\end{array}$ & $\mathrm{Ib}$ \\
\hline
\end{tabular}

T: treatment group; C: control group.

TABLE 3: Sports intervention features in the included literature.

\begin{tabular}{|c|c|c|c|c|c|c|c|}
\hline \multirow[b]{2}{*}{ No. } & \multirow[b]{2}{*}{$\begin{array}{l}\text { Included in the } \\
\text { study }\end{array}$} & \multicolumn{2}{|c|}{ Intervention measures } & \multicolumn{3}{|c|}{ Intervention elements } & \multirow[b]{2}{*}{$\begin{array}{l}\text { Outcome } \\
\text { indicators }\end{array}$} \\
\hline & & Treatment group & Control group & $\begin{array}{l}\text { Control } \\
\text { group }\end{array}$ & $\begin{array}{l}\text { Frequency } \\
\text { (times/wk) }\end{array}$ & Time (min/time) & \\
\hline 1 & $\begin{array}{l}\text { Au-Yeung } \\
\text { et al. [16] }\end{array}$ & Tai Chi & Regular activity & 12 & 4 & 60 & TUG \\
\hline 2 & $\begin{array}{l}\text { Chan and } \\
\text { Tsang [17] }\end{array}$ & Tai Chi & Regular activity & 12 & 2 & 60 & $\begin{array}{c}\text { Gravity swing } \\
\text { test }\end{array}$ \\
\hline 3 & $\begin{array}{c}\text { Huang et al. } \\
{[18]}\end{array}$ & Tai Chi & Regular activity & 12 & 3 & 40 & FMA \\
\hline 4 & Kim et al. [19] & Tai Chi + physiotherapy & Physiotherapy & 6 & 2 & 60 & TUG, $10 \mathrm{mwt}$ \\
\hline
\end{tabular}


TABLE 3: Continued.

\begin{tabular}{|c|c|c|c|c|c|c|c|}
\hline \multirow[b]{2}{*}{ No. } & \multirow{2}{*}{$\begin{array}{l}\text { Included in the } \\
\text { study }\end{array}$} & \multicolumn{2}{|c|}{ Intervention measures } & \multicolumn{3}{|c|}{ Intervention elements } & \multirow[b]{2}{*}{$\begin{array}{l}\text { Outcome } \\
\text { indicators }\end{array}$} \\
\hline & & Treatment group & Control group & $\begin{array}{l}\text { Control } \\
\text { group }\end{array}$ & $\begin{array}{l}\text { Frequency } \\
\text { (times/wk) }\end{array}$ & Time (min/time) & \\
\hline 5 & $\begin{array}{l}\text { Taylor-Piliae } \\
\text { and Coull [20] }\end{array}$ & Tai Chi & Health education & 12 & 3 & 60 & SPPB \\
\hline 6 & $\begin{array}{l}\text { Taylor-Piliae } \\
\text { et al. [21] }\end{array}$ & Tai Chi & Regular activity & 12 & 3 & 60 & SPPB \\
\hline 7 & $\begin{array}{l}\text { Zheng et al. } \\
\text { [22] }\end{array}$ & Tai Chi & Regular activity & 12 & 5 & 60 & $6 \mathrm{mwt}$ \\
\hline 8 & Fan et al. [23] & $\begin{array}{c}\text { Tai } \mathrm{Chi}+\text { conventional } \\
\text { rehabilitation }\end{array}$ & $\begin{array}{l}\text { Conventional } \\
\text { rehabilitation }\end{array}$ & 12 & 3 & 90 & $\begin{array}{l}\text { BBS, TUG, } \\
\text { and FMA }\end{array}$ \\
\hline 9 & $\begin{array}{c}\text { Fu and Zhang } \\
{[24]}\end{array}$ & $\begin{array}{c}\text { Tai Chi + conventional } \\
\text { rehabilitation }\end{array}$ & $\begin{array}{l}\text { Conventional } \\
\text { rehabilitation }\end{array}$ & 8 & 6 & 40 & BBS \\
\hline 10 & Li et al. [25] & Tai Chi + medicine & Medicine & 12 & 2 & 60 & FMA \\
\hline 11 & Liu et al. [26] & $\begin{array}{l}\text { Tai Chi + conventional } \\
\text { rehabilitation }\end{array}$ & $\begin{array}{l}\text { Conventional } \\
\text { rehabilitation }\end{array}$ & 12 & 7 & 30 & BBS \\
\hline 12 & Xiao [27] & $\begin{array}{c}\text { Tai Chi + conventional } \\
\text { rehabilitation }\end{array}$ & $\begin{array}{l}\text { Conventional } \\
\text { rehabilitation }\end{array}$ & - & 5 & 40 & FMA \\
\hline 13 & Xu et al. [28] & Tai Chi + physiotherapy & Physiotherapy & 12 & 7 & 40 & BBS \\
\hline 14 & $\begin{array}{c}\text { Yang and Liu } \\
{[29]}\end{array}$ & $\begin{array}{c}\text { Tai } \text { Chi + conventional } \\
\text { rehabilitation }\end{array}$ & $\begin{array}{l}\text { Conventional } \\
\text { rehabilitation }\end{array}$ & 8 & 3 & 40 & FMA \\
\hline 15 & $\begin{array}{c}\text { Yang and Tang } \\
{[30]}\end{array}$ & $\begin{array}{c}\text { Tai Chi + comprehensive } \\
\text { rehabilitation }\end{array}$ & $\begin{array}{l}\text { Comprehensive } \\
\text { rehabilitation }\end{array}$ & 8 & 5 & 40 & FMA and BBS \\
\hline 16 & Yang et al. [31] & $\begin{array}{c}\text { Tai Chi + traditional } \\
\text { walking }\end{array}$ & Traditional walking & - & 7 & $\begin{array}{c}15 \text { (Tai Chi) }+45 \\
\text { (traditional } \\
\text { walking) }\end{array}$ & FMA \\
\hline 17 & $\begin{array}{c}\text { Zhang et al. } \\
\text { [32] }\end{array}$ & $\begin{array}{c}\text { Tai } \mathrm{Chi}+\text { conventional } \\
\text { rehabilitation }\end{array}$ & $\begin{array}{l}\text { Conventional } \\
\text { rehabilitation }\end{array}$ & 3 & 7 & 30 & FMA \\
\hline 18 & Zhao et al. [33] & $\begin{array}{c}\text { Tai Chi + conventional } \\
\text { rehabilitation }\end{array}$ & $\begin{array}{l}\text { Conventional } \\
\text { rehabilitation }\end{array}$ & 8 & 5 & 30 & FMA \\
\hline 19 & Yi et al. [34] & $\begin{array}{c}\text { Tai Chi + conventional } \\
\text { rehabilitation }\end{array}$ & $\begin{array}{l}\text { Conventional } \\
\text { rehabilitation }\end{array}$ & 12 & 2 & 60 & $\begin{array}{l}\text { BBS, FMA, } \\
\text { and swing test }\end{array}$ \\
\hline
\end{tabular}

"-" indicates that there is no description in the literature; TUG: timed up and go test; FMA: Fugl-Meyer motor function score scale; $10 \mathrm{mwt}: 10 \mathrm{~m}$ walking test; SPPB: short physical performance battery; 6 mwt: $6 \mathrm{~m}$ walking test; BBS: Berg Balance Scale.

standing, but it has no statistical significance on the length of the gravity center swing.

3.3.5. The Influences of Tai Chi on FMA. Ten papers analyzed the influence of Tai Chi on the FMA scale. The heterogeneity analysis results showed that $I^{2}=98 \%, P<0.01$. Therefore, a meta-analysis of the results using a random effects model showed that $[\mathrm{MD}=4.15,95 \% \mathrm{CI}(1.68,6.63)]$. Compared with the control group, Tai Chi can significantly improve the FMA scale scores of stroke patients, or the exercise ability improved significantly.

Two papers selected once-twice/wk exercise frequency for Tai Chi intervention, whose combined effect size showed $[M D=9.46,95 \%$ CI $(0.92,17.99)]$. Three studies selected 3-4 times/wk exercise frequency for Tai Chi exercise, whose combined effect size showed $[\mathrm{MD}=3.66$, $95 \%$ CI $(-0.50,7.82)]$. Five papers studied exercise frequency $\geq 5$ times/wk, whose combined effect size was $[\mathrm{MD}=1.76,95 \% \mathrm{CI}(0.56,2.95)]$. The results show that 3-4 times/wk of Tai Chi exercises cannot significantly improve the FMA scale scores of patients, while oncetwice/wk and $\geq 5$ times/wk of Tai Chi exercises can significantly improve FMA scores and improve exercise ability of patients (Figure 10).
Three papers selected Tai Chi exercises lasting for $\leq 30 \mathrm{~min} /$ time, whose combined effect size was $[\mathrm{MD}=2.89,95 \% \mathrm{CI}(0.03$, 5.75)]. Seven papers studied 30-60 min per time Taijiquan exercises, whose combined the effect size was $[\mathrm{MD}=4.64,95 \%$ CI $(0.70,8.57)]$. The results show that both kinds of exercise duration can improve the FMA scale score and improve exercise ability, while the improvement effect of 30-60 $\mathrm{min} /$ time exercise time is better (Figure 11).

3.3.6. The Impact of Tai Chi on SPPB. Two papers studied the influence of Tai Chi on the SPPB scale. The heterogeneity analysis showed that $I^{2}=0 \%, P=0.92>0.05$, that is, the two studies did not have statistical heterogeneity, so the fixedeffects model was selected for meta-analysis of the results. The combined effect size was $[\mathrm{MD}=-0.22,95 \%$ CI $(-1.00$, 0.56)], that is, Tai Chi exercise has no significant improvement effect on SPPB and it cannot significantly improve the exercise capacity of stroke patients (Figure 12).

\section{Discussion and Analysis}

4.1. The Overall Analysis of the Impact of Tai Chi on the Balance Function and Exercise Ability of Stroke Patients. The results of this study prove that Tai Chi is able to significantly 


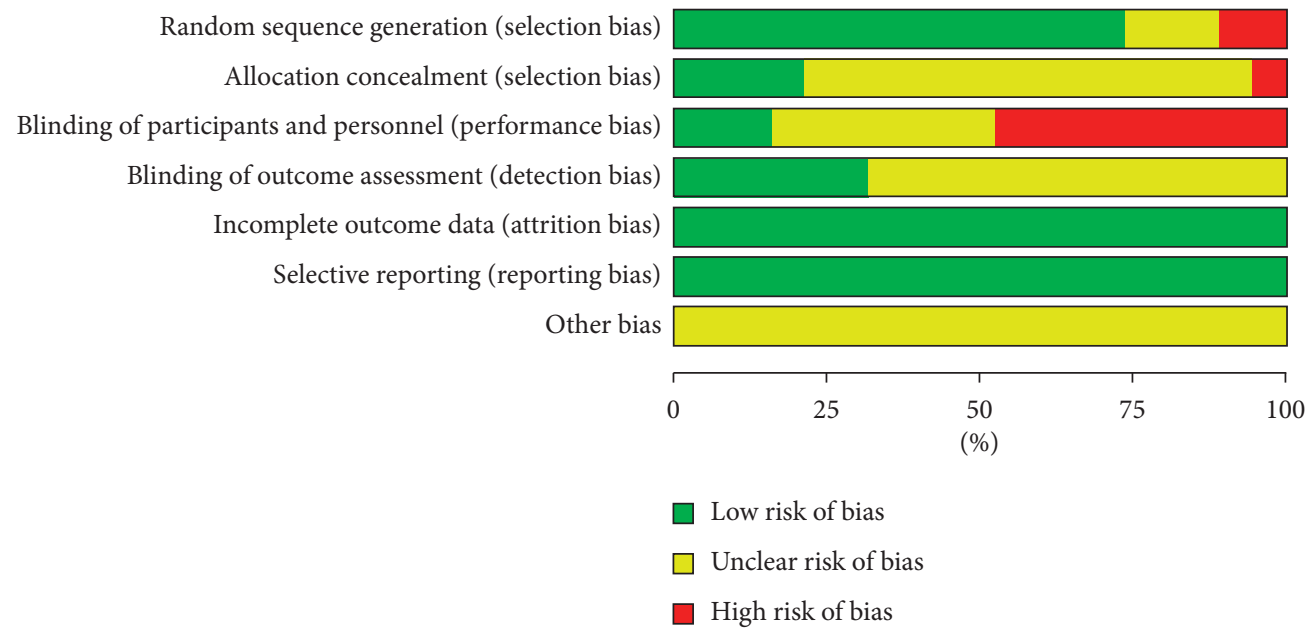

Figure 2: The overall risk of bias of the included papers.
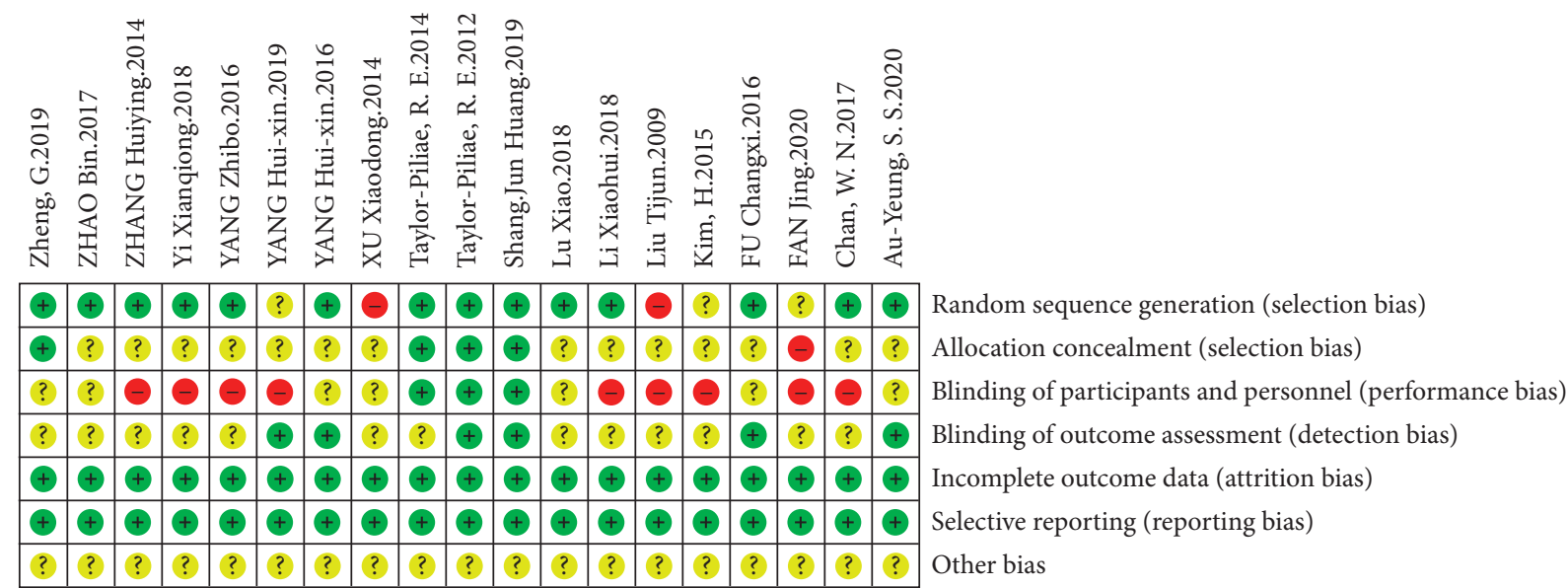

Figure 3: The risk of bias of the included papers.

\begin{tabular}{|c|c|c|c|c|c|c|c|c|c|c|c|c|c|}
\hline \multirow{3}{*}{$\begin{array}{l}\text { Study or subgroup } \\
\text { FAN Jing, } 2020\end{array}$} & \multicolumn{3}{|c|}{ Intervention group } & \multicolumn{3}{|c|}{ Control group } & \multirow{2}{*}{$\begin{array}{c}\text { Weight } \\
(\%)\end{array}$} & \multirow{2}{*}{\multicolumn{2}{|c|}{$\begin{array}{c}\text { Mean difference } \\
\text { IV, random, 95\% CI }\end{array}$}} & \multirow{2}{*}{\multicolumn{3}{|c|}{$\begin{array}{c}\text { Mean difference } \\
\text { IV, random, 95\% CI }\end{array}$}} & \\
\hline & \multirow{2}{*}{$\begin{array}{l}\text { Mean } \\
11.85\end{array}$} & \multirow{2}{*}{$\frac{\mathrm{SD}}{2.96}$} & \multirow{2}{*}{$\begin{array}{c}\text { Total } \\
43\end{array}$} & \multirow{2}{*}{$\frac{\text { Mean }}{7.03}$} & \multirow{2}{*}{$\frac{\mathrm{SD}}{2.6}$} & \multirow{2}{*}{$\begin{array}{c}\text { Total } \\
0\end{array}$} & & & & & & & \\
\hline & & & & & & & & Not estimable & & & & & \\
\hline FU Changxi, 2016 & 16.15 & 8.83 & 30 & 6.4 & 8.83 & 30 & 17.7 & $9.75(5.39,14.11)$ & & & & & \\
\hline Liu Tijun, 2009 & 29.4 & 8.09 & 24 & 14.15 & 8.09 & 24 & 17.4 & $15.25(10.67,19.83)$ & & & & & - \\
\hline XU Xiaodong, 2014 & 29.77 & 1.25 & 40 & 22.56 & 1.32 & 40 & 21.7 & $7.21(6.65,7.77)$ & & & & - & \\
\hline YANG Hui-xin, 2016 & 0.64 & 1.14 & 28 & 0.28 & 0.7 & 28 & 21.7 & $0.36(-0.16,0.88)$ & & & 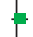 & & \\
\hline Yi Xianqiong, 2018 & 26.48 & 3.17 & 66 & 18.78 & 3.2 & 66 & 21.5 & $7.70(6.61,8.79)$ & & & & - & \\
\hline \multicolumn{3}{|l|}{ Total (95\% CI) } & 231 & & & 181 & 100.0 & $7.67(3.44,11.90)$ & & & & & \\
\hline \multicolumn{9}{|c|}{ Heterogeneity: $\operatorname{tau}^{2}=21.36 ; \mathrm{chi}^{2}=388.99, \mathrm{df}=4(P<0.00001) ; I^{2}=99 \%$} & & & & $T$ & $T$ \\
\hline \multicolumn{9}{|c|}{ Test for overall effect: $Z=3.56(P=0.0004)$} & -20 & -10 & 0 & 10 & 20 \\
\hline & & & & & & & & & \multicolumn{5}{|c|}{ Control intervention } \\
\hline
\end{tabular}

FIgURE 4: The forest diagram of the influences of Tai Chi on the BBS.

improve the balance function and exercise ability of stroke patients. This result is consistent with previous study results and again verifies the results of previous studies. Studies have shown that the stability of the core muscles of stroke patients is weak, and the stability of the trunk and pelvis is poor when completing antigravity activities, which leads to weakened exercise capacity [35] and decreased balance ability [36] during walking. As a low-intensity exercise method, Tai Chi can relax the tense muscles of patients, increase muscle flexibility and strength, improve the normal movement control ability of stroke patients, improve balance function, and inhibit the occurrence of abnormal postures and spasms, as well as have a positive effect on the life quality and psychological emotions of patients $[7,37,38]$. The study also found that regular Tai Chi exercises can promote the formation of functional nerve 


\begin{tabular}{|c|c|c|c|c|c|c|c|c|c|c|c|c|c|}
\hline \multirow{3}{*}{$\begin{array}{l}\text { Study or subgroup } \\
\text { AU-Yeung, S. S, } 2009\end{array}$} & \multicolumn{3}{|c|}{ Intervention group } & \multicolumn{3}{|c|}{ Control group } & \multirow{2}{*}{$\begin{array}{l}\text { Weight } \\
(\%)\end{array}$} & \multirow{2}{*}{$\begin{array}{l}\text { Mean difference } \\
\text { IV, fixed, 95\% CI }\end{array}$} & \multirow{2}{*}{\multicolumn{5}{|c|}{$\begin{array}{l}\text { Mean difference } \\
\text { IV, fixed, 95\% CI }\end{array}$}} \\
\hline & \multirow{2}{*}{$\begin{array}{l}\text { Mean } \\
-4.2\end{array}$} & \multirow{2}{*}{$\frac{\mathrm{SD}}{16.84}$} & \multirow{2}{*}{$\begin{array}{c}\text { Total } \\
59\end{array}$} & \multirow{2}{*}{$\begin{array}{c}\text { Mean } \\
-1.7\end{array}$} & \multirow{2}{*}{$\frac{\mathrm{SD}}{22.52}$} & \multirow{2}{*}{$\begin{array}{c}\text { Total } \\
55\end{array}$} & & & & & & & \\
\hline & & & & & & & 1.2 & $-2.50(-9.84,4.84)$ & & & & & \\
\hline FAN Jing, 2020 & -7.67 & 2.84 & 43 & -3.53 & 2.93 & 43 & 42.2 & $-4.14(-5.36,-2.92)$ & & & & & \\
\hline Kim, H, 2015 & -3.73 & 1.27 & 11 & -0.82 & 1.25 & 11 & 56.6 & $-2.91(-3.86,-1.86)$ & & & & & \\
\hline Total $(95 \%$ CI) & & & 113 & & & 109 & 100.0 & $-3.42(-4.22,-2.63)$ & & & & & \\
\hline \multicolumn{9}{|c|}{ Heterogeneity: $\mathrm{chi}^{2}=2.30, \mathrm{df}=2(P=0.32) ; I^{2}=13 \%$} & $\Gamma$ & & & $\top$ & $T$ \\
\hline \multicolumn{9}{|c|}{ Test for overall effect: $Z=8.47(P<0.00001)$} & -10 & -5 & 0 & 5 & 10 \\
\hline & & & & & & & & & \multicolumn{5}{|c|}{ Intervention control } \\
\hline
\end{tabular}

Figure 5: Forest diagram of the influences of Tai Chi on the standing and walking test.

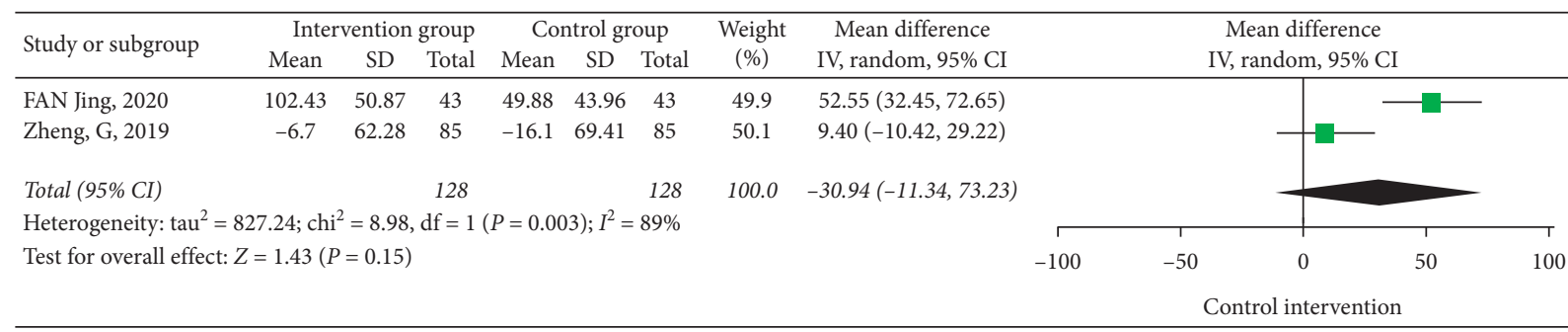

FIgURE 6: Forest diagram of the influences of Tai Chi on the $6 \mathrm{~m}$ walking experiment.

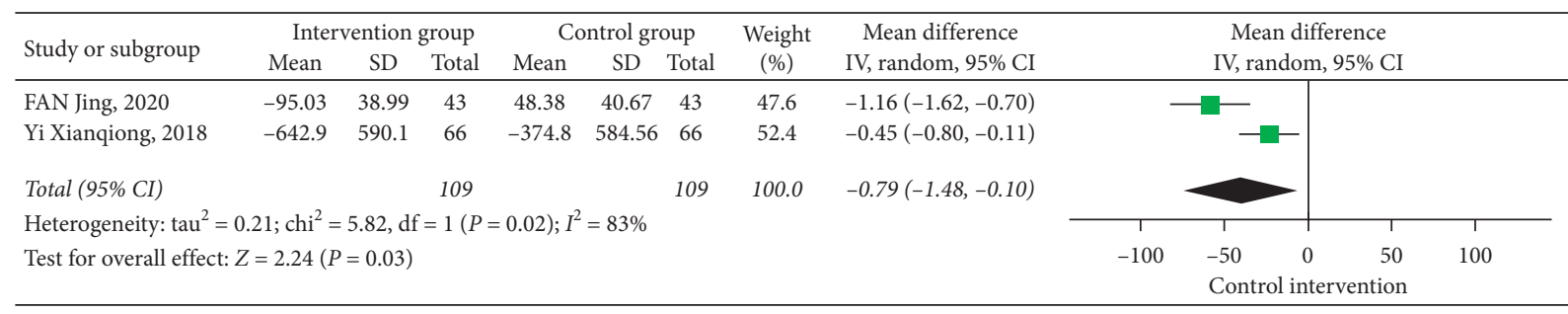

Figure 7: Forest diagram of the influences of Tai Chi on the swing area of the gravity center.

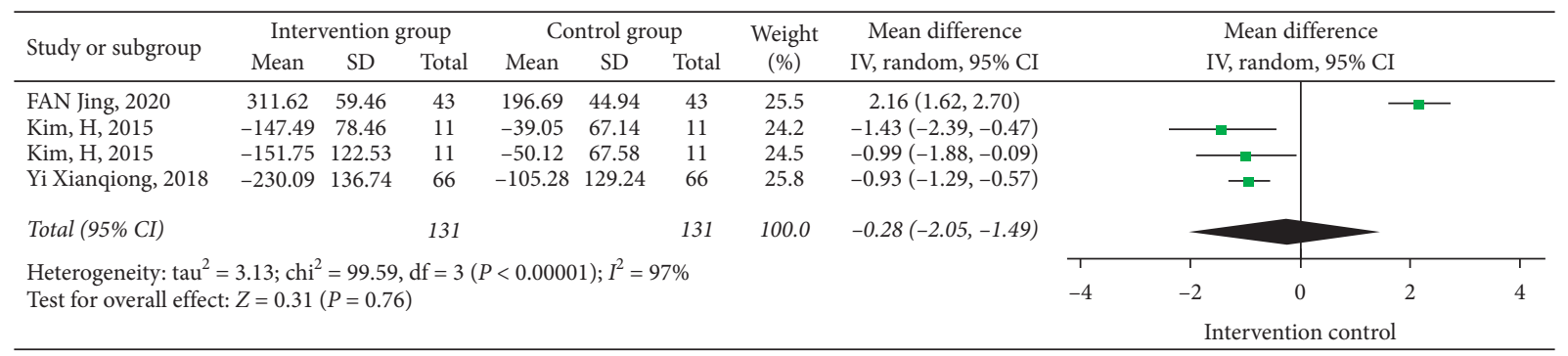

FIgURE 8: Forest diagram of the influences of Tai Chi on the swing length of the gravity center.

\begin{tabular}{|c|c|c|c|c|c|c|c|c|c|c|c|c|c|}
\hline \multirow{3}{*}{$\begin{array}{l}\text { Study or subgroup } \\
\text { Chan, W. N, } 2017\end{array}$} & \multicolumn{3}{|c|}{ Intervention group } & \multicolumn{3}{|c|}{ Control group } & \multirow{3}{*}{$\begin{array}{c}\text { Weight } \\
(\%)\end{array}$} & \multirow{3}{*}{$\begin{array}{c}\text { Mean difference } \\
\text { IV, fixed, 95\% CI } \\
4.40(-20.75,29.55)\end{array}$} & \multirow{2}{*}{\multicolumn{5}{|c|}{$\begin{array}{l}\text { Mean difference } \\
\text { IV, fixed, } 95 \% \text { CI }\end{array}$}} \\
\hline & \multirow{2}{*}{$\begin{array}{c}\text { Mean } \\
-3.8\end{array}$} & \multirow{2}{*}{$\frac{\mathrm{SD}}{31.3}$} & \multirow{2}{*}{$\begin{array}{c}\text { Total } \\
9\end{array}$} & \multirow{2}{*}{$\begin{array}{c}\text { Mean } \\
-8.2\end{array}$} & \multirow{2}{*}{$\frac{\mathrm{SD}}{22.4}$} & \multirow{2}{*}{$\begin{array}{c}\text { Total } \\
9\end{array}$} & & & & & & & \\
\hline & & & & & & & & & & & & & \\
\hline Kim, H, 2015 & -8.32 & 4.45 & 11 & -2.31 & 2.57 & 11 & $60.1 \%$ & $-6.01(-9.05,-2.97)$ & & - & & & \\
\hline Kim, H, 2015 & -5.86 & 5.49 & 11 & -1.1 & 3.25 & 11 & $39.0 \%$ & $-4.76(-8.53,-0.99)$ & & & & & \\
\hline Total (95\% CI) & & & 31 & & & 31 & $100.0 \%$ & $-5.43(-7.79,-3.08)$ & & & & & \\
\hline \multicolumn{9}{|c|}{ Heterogeneity: $\mathrm{chi}^{2}=0.85, \mathrm{df}=2(P=0.65) ; I^{2}=0 \%$} & & & & $T$ & $T$ \\
\hline \multicolumn{9}{|c|}{ Test for overall effect: $Z=4.52(P<0.00001)$} & -20 & -10 & 0 & 10 & 20 \\
\hline & & & & & & & & & \multicolumn{5}{|c|}{ Intervention control } \\
\hline
\end{tabular}

FIgURE 9: The forest diagram of the influences of Tai Chi on the swing speed of the gravity center. 


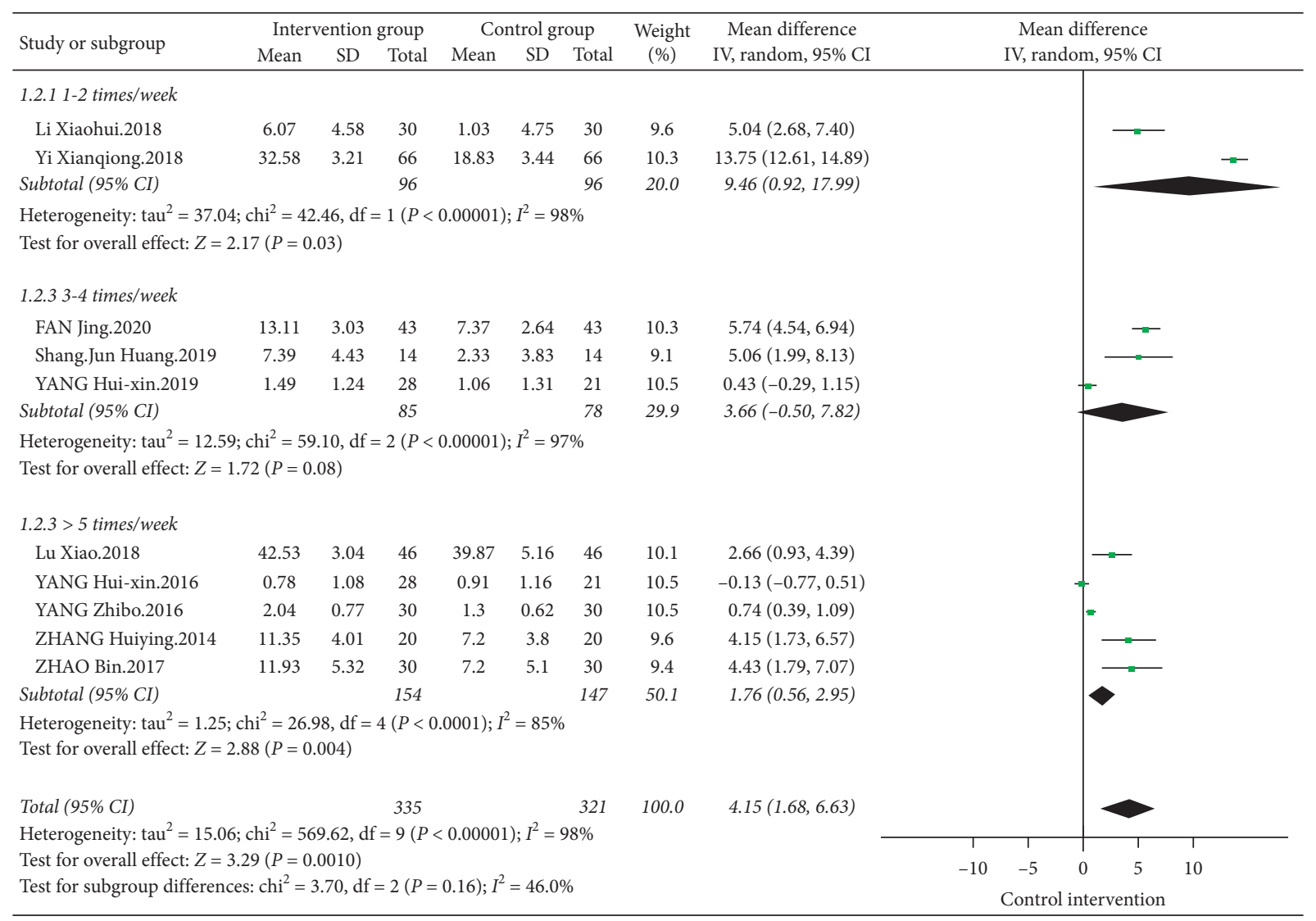

FIGURE 10: Forest diagram of the influences of different exercise frequencies on FMA.

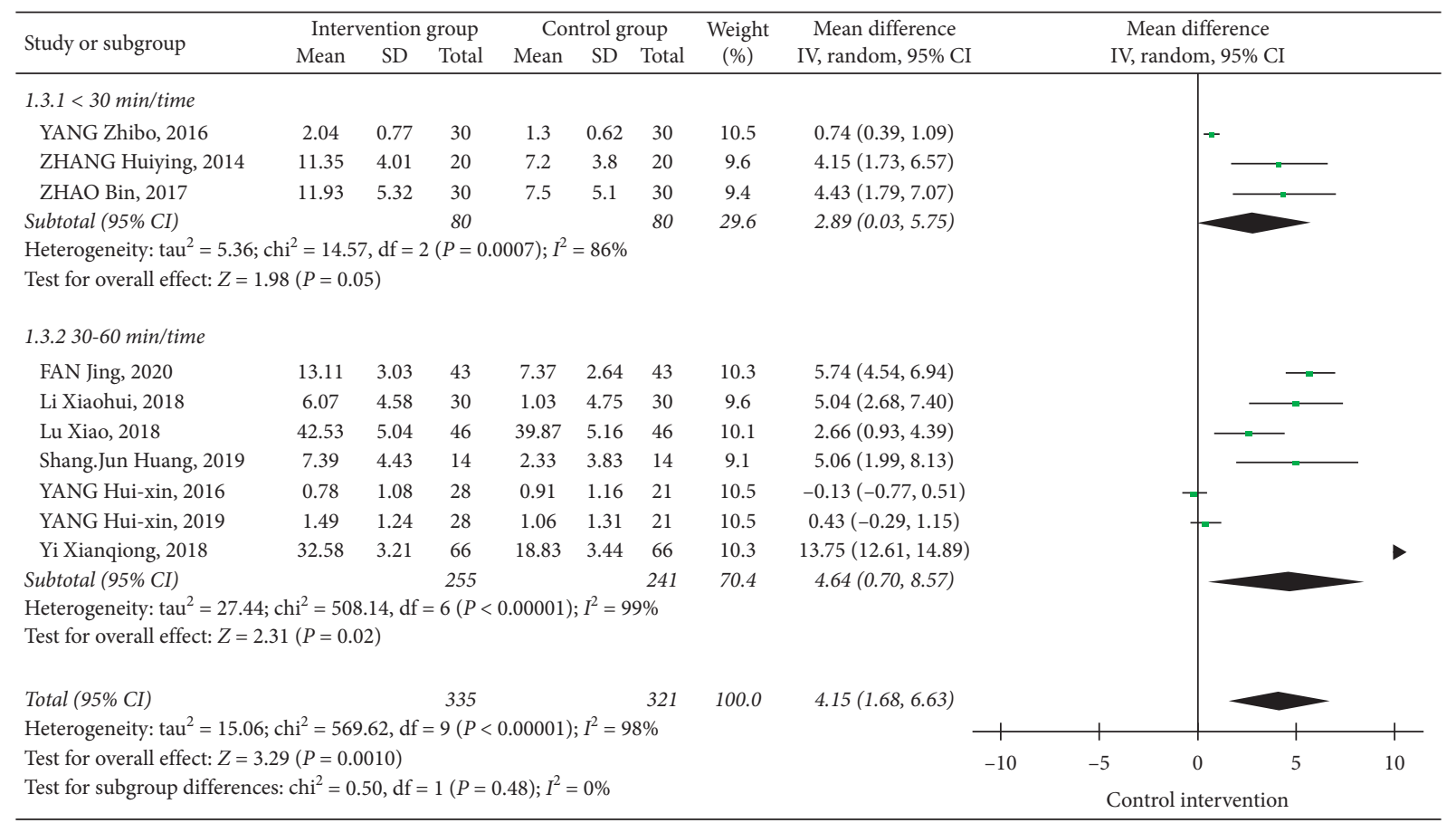

Figure 11: Forest diagram of the influences of different exercise durations on FMA. 


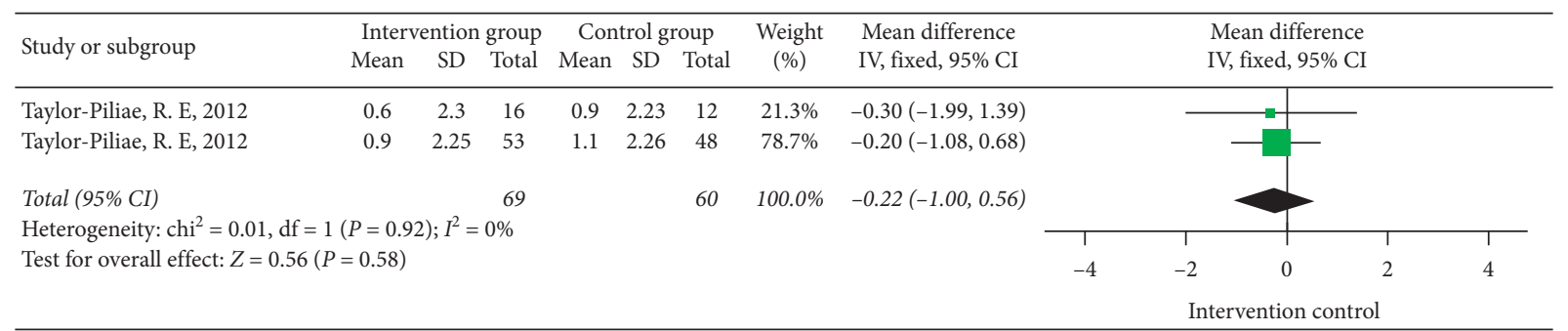

FIgURE 12: The forest diagram of the impact of Tai Chi on SPPB.

pathways, consolidate the efficiency of newly created or newly activated synapses, improve peripheral nerve conduction function, enhance the proprioception ability, promote exercise ability, and improve the quality of life [39].

4.2. The Effects of Physical Exercise Variables on the Balance Function and Exercise Ability among Stroke Patients. These studies show that Tai Chi exercises with different time durations all have a significant improvement on the balance function and exercise ability of stroke patients, among which $>30 \leq 60 \mathrm{~min} /$ time has the best effect on the patient's exercise ability. They also show that patients have not only improved their balance function and exercise performance but also significantly promoted the life quality index [40]. Another study found that, after Tai Chi exercises, upper limb function of stroke patients improved significantly, and the coordination and balance of the lower limbs also improved to some extent. Follow-up studies also found that their exercise ability and life activity ability also improve [41].

Tai Chi exercises at different frequencies each week have different effects on the balance function and exercise ability of stroke patients. Tai Chi frequency of twice a week by Hwang et al. [42] shows that the balance ability, coordination, and walking ability have significantly improved among stroke patients, which are essential for them to take care of themselves in daily life and prevent from falling down [43]. Studies have found that Tai Chi can increase the strength of the quadriceps and hamstrings, improve flexibility, thereby enhance the stability and balance of the knee joint, and improve the exercise ability of patients $[44,45]$. In another frequency study by Wang et al. [46], after 5 times/wk of Tai Chi Cloud Hand training, the Berg Balance Scale score of the experimental group improved significantly, indicating that Tai Chi can promote the balance function of stroke patients. The study by Yang et al. [47] also found that 5 times/wk of Tai Chi exercises can adjust the exercise ability of the patients, thereby promoting gait stability.

The experimental cycles included in this study are all 12 weeks or less. The results show that the balance function and exercise ability of stroke patients in the treatment group improved significantly. A large number of previous studies have also disclosed the effect of a certain period of Tai Chi exercise on stroke patients. Hart et al. conducted 12-week Tai Chi exercise training for stroke patients on a community basis, whose results showed that the stroke patients improved in terms of balance function and exercise ability [48]. In another 12-week Tai Chi "Cloud Hand" intervention for stroke patients, the control group received routine rehabilitation training, evaluating the balance function and exercise ability through the Berg Balance Scale, as well as the standing and walking test, and the balance function and exercise ability of both groups improved. In the mean time, as the intervention period extended, Tai Chi had better influences on the balance function and exercise ability. Yu et al. analyzed the effect of Tai Chi for 24 weeks on the static balance of middle-aged and elderly people and found that the total length of the gravity center movement of the subjects, the peripheral area, and the shaking index of the surrounding area significantly improved, which shows the promotion of static balance ability of Tai Chi among the middle-aged and elderly people $[49,50]$.

\section{Limitations}

This study has certain limitations. First, the research methods of some included papers are not comprehensive, which did not explain the method of random allocation or blinding the subjects or evaluator. Therefore, the results may be inaccurate. Second, certain results of meta-analyses are highly heterogeneous. As a result, the research results may have a certain degree of bias. Third, some studies have small number of subjects and a small sample size, which suggests that more experimental studies are needed to prove our point of view.

\section{Conclusions}

Stroke has become a prominent problem that seriously endangers the health of middle-aged and elderly people, which features high morbidity, high disability, and high mortality. Tai Chi is considered as an effective nondrug intervention against hemiplegia, which is one of the most common sequelae of stroke patients. This study used the meta-analysis method to analyze the randomized controlled study on the intervention of Tai Chi on balance function and exercise ability among stroke patients, which further proved that Tai Chi can significantly enhance balance function and exercise ability of stroke patients. This study also analyzed the dose-response relationship of balance function and exercise ability when doing Tai Chi. Study results show that regular Tai Chi exercise once to twice a week, $\geq 5$ times/wk, and $>30 \leq 60 \mathrm{~min} /$ time can improve the balance function and exercise capability of the stroke patients.

In the future, the study should consider the safety and effectiveness of Taijiquan intervention for stroke patients. 
Moreover, study in this filed should adopt comprehensive randomized controlled studies as much as possible, improve the methodological quality, strengthen the research on balance function and exercise ability of stroke patients, ensure the quality of evidence in research, enrich the research on different schemes of Tai Chi intervention, and improve the dose-response relationship between exercise variables of Tai Chi and balance function and Tai Chi and exercise ability among stroke patients.

\section{Conflicts of Interest}

The authors declare that they have no conflicts of interest.

\section{Acknowledgments}

This work was supported by the Key Laboratory Project of Shanghai Science and Technology Commission (11DZ2261100) and the National Social Science Foundation (20BTY116).

\section{References}

[1] S. Yao, "The application and nursing of hemiplegia treatment instrument combined with graded functional training in cerebral infarction patients," Tianjin Journal of Nursing, vol. 26, no. 1, pp. 75-76, 2018.

[2] Z. Liu, "The application effect of hemiplegia limb rehabilitation training nursing in cerebral infarction nursing," Journal of Clinic Nursing's Practicality, vol. 3, no. 12, p. 37, 2018.

[3] J. D. Horowitz, R. De Caterina, T. Heresztyn et al., "Asymmetric and symmetric dimethylarginine predict outcomes in patients with atrial fibrillation," Journal of the American College of Cardiology, vol. 72, no. 7, pp. 721-733, 2018.

[4] N. Akutagawa, S. Sadashima, H. Nakagaki, S. Nagano, and T. Yoshimura, "Intracerebral hemorrhage after intravenous recombinant tissue plasminogen activator (rt-PA) therapy for acute cerebral infarction in a patient with ANCA-associated vasculitis," Rinsho Shinkeigaku, vol. 57, no. 8, pp. 454-456, 2017.

[5] S. L. Guo, S. Chen, S. Y. Huang et al., "Advances in research on the effect of Taijiquan exercise on stroke patients with hemiplegia," Journal of Luoyang Normal University, vol. 38, no. 8, pp. 44-50, 2019.

[6] A. Voukelatos, R. G. Cumming, S. R. Lord, and C. Rissel, “A randomized, controlled trial of Tai Chi for the prevention of falls: the central Sydney Tai Chi trial," Journal of the American Geriatrics Society, vol. 55, no. 8, pp. 1185-1191, 2007.

[7] F. Li, P. Harmer, K. Fitzgerald et al., "Tai Chi and postural stability in patients with Parkinson's disease," New England Journal of Medicine, vol. 366, no. 6, pp. 511-519, 2012.

[8] C. Wang, C. H. Schmid, R. Rones et al., "A randomized trial of Tai Chi for fibromyalgia," New England Journal of Medicine, vol. 363 , no. 8, pp. 743-754, 2010.

[9] A. Liberati, D. G. Altman, J. Tetzlaff et al., "The PRISMA statement for reporting systematic reviews and meta-analyses of studies that evaluate health care interventions: explanation and elaboration," PLoS Medicine, vol. 6, no. 7, p. 418, 2009.

[10] "Key points for diagnosis of various cerebrovascular diseases," Chinese Journal of Neurology, pp. 60-61, 1996.

[11] W. J. Powers, A. A. Rabinstein, T. Ackerson et al., "Guidelines for the early management of patients with acute ischemic stroke: 2019 update to the 2018 guidelines for the early management of acute ischemic stroke: a guideline for healthcare professionals from the American heart association/ American stroke association," Stroke, vol. 50, no. 12, pp. e344-e418, 2019.

[12] K. I. Erickson, C. Hillman, C. M. Stillman et al., "Physical activity, cognition, and brain outcomes," Medicine \& Science in Sports \& Exercise, vol. 51, no. 6, pp. 1242-1251, 2019.

[13] C. E. Garber, B. Blissmer, M. R. Deschenes et al., "Quantity and quality of exercise for developing and maintaining cardiorespiratory, musculoskeletal, and neuromotor fitness in apparently healthy adults," Medicine \& Science in Sports \& Exercise, vol. 43, no. 7, pp. 1334-1359, 2011.

[14] S. Colcombe and A. F. Kramer, "Fitness effects on the cognitive function of older adults a meta-analytic study," Psychological Science, vol. 14, no. 2, pp. 125-130, 2003.

[15] P. Fusaroli, B. Napoleon, R. Gincul et al., "The clinical impact of ultrasound contrast agents in EUS: a systematic review according to the levels of evidence," Gastrointestinal Endoscopy, vol. 84, no. 4, pp. 587-596, 2016.

[16] S. S. Y. Au-Yeung, C. W. Y. Hui-Chan, and J. C. S. Tang, "Short-form Tai Chi improves standing balance of people with chronic stroke," Neurorehabilitation and Neural Repair, vol. 23, no. 5, pp. 515-522, 2009.

[17] W.-N. Chan and W. W.-N. Tsang, "Effect of Tai Chi training on dual-tasking performance that involves stepping down among stroke survivors: a pilot study," Evidence-Based Complementary and Alternative Medicine, vol. 2017, Article ID 9134173, 12 pages, 2017.

[18] S. Huang, X. Yu, Y. Lu et al., "Body weight support-Tai Chi footwork for balance of stroke survivors with fear of falling: a pilot randomized controlled trial," Complementary Therapies in Clinical Practice, vol. 37, pp. 140-147, 2019.

[19] H. Kim, Y. L. Kim, and S. M. Lee, "Effects of therapeutic Tai Chi on balance, gait, and quality of life in chronic stroke patients," International Journal of Rehabilitation Research, vol. 38, no. 2, pp. 156-161, 2015.

[20] R. E. Taylor-Piliae and B. M. Coull, "Community-based Yangstyle Tai Chi is safe and feasible in chronic stroke: a pilot study," Clinical Rehabilitation, vol. 26, no. 2, pp. 121-131, 2012.

[21] R. E. Taylor-Piliae, T. M. Hoke, J. T. Hepworth, L. D. Latt, B. Najafi, and B. M. Coull, "Effect of Tai Chi on physical function, fall rates and quality of life among older stroke survivors," Archives of Physical Medicine and Rehabilitation, vol. 95, no. 5, pp. 816-824, 2014.

[22] G. Zheng, X. Zheng, J. Li et al., "Effects of tai chi on cerebral hemodynamics and health-related outcomes in older community adults at risk of ischemic stroke: a randomized controlled trial," Journal of Aging and Physical Activity, vol. 27, no. 5, pp. 678-687, 2019.

[23] J. Fan, Y. P. Guo, and P. F. Guo, "Effect of modified Tai Chi on balance in stroke patients and on serum alkaline phosphatase, neuropeptide $\mathrm{Y}$ and interleukin-6 expression," Chinese Journal of Multiple Organ Diseases in the Elderly, vol. 19, no. 2, pp. 103-108, 2020.

[24] C. X. Fu and Q. Y. Zhang, "Effects of Taijiquan on balance function and walking ability of stroke hemiplegic patients in convalescent phase," Chinese Journal of Rehabilitation Medicine, vol. 31, no. 5, pp. 536-539, 2016.

[25] X. H. Li, P. Liu, B. Xiong et al., "Clinical study of modified 24style Taijiquan on post-stroke depression," Chinese Journal of Health Care Medicine, vol. 20, no. 5, pp. 434-435, 2018.

[26] T. J. Liu, P. Qin, and X. Z. Chen, "Effect of Taijiquan on balance function in stroke patients," Chinese Journal of 
Physical Medicine and Rehabilitation, vol. 31, no. 11, pp. 781-782, 2009.

[27] L. Xiao, "Effect of improved Taijiquan on motor function rehabilitation after stroke," Medical Diet and Health, no. 9, p. 231, 2018.

[28] X. D. Xu, J. Bai, H. L. Zhang et al., "Analysis of curative effect for Tai Chi on the balance function of patients with hemiplegia after stroke," Hebei Journal of Traditional Chinese Medicine, vol. 36, no. 8, pp. 1149-1151, 2014.

[29] H. X. Yang and X. L. Liu, "Effects of Taiji Quan and Baduanjin on motor function of lower limbs for stroke patients using surface electromyography," Chinese Journal of Rehabilitation Theory and Practice, vol. 25, no. 1, pp. 101-106, 2019.

[30] H. X. Yang and Q. Tang, "Clinical observation of Tai Chi for rehabilitation of motor dysfunction in stroke patients," Chinese Journal of Rehabilitation Medicine, vol. 31, no. 10, pp. 1146-1148, 2016.

[31] Z. B. Yang, D. Liu, Y. S. Chang et al., "Clinical analysis on TaiChi balance therapeutics for post-stroke hemiplegia with walking dysfunction," Chinese Medicine Modern Distance Education of China, vol. 14, no. 15, pp. 81-83, 2016.

[32] H. Y. Zhang, Y. Y. Qing, Y. Q. Zhang et al., "Effects of Tai-Ji exercise motor imagery on walk function of patients with hemiplegia after stroke," Journal of Shanghai Jiaotong University (Medical Science), vol. 34, no. 9, pp. 1268-1271+75, 2014.

[33] B. Zhao, Q. Tang, Y. Wang et al., "Effects of Taijiquan on motor function and depression in patients with post-stroke depression," Chinese Journal of Rehabilitation Theory and Practice, vol. 23, no. 3, pp. 334-337, 2017.

[34] X. Q. Yi, W. Z. Zhu, Y. X. Jin et al., "A study on the effect of Taiji Yunh and training on balance dysfunction after stroke," Nursing and Rehabilitation Journal, vol. 17, no. 3, pp. 69-72, 2018.

[35] I. Keser, N. Kirdi, A. Meric, A. Tuncer Kurne, and R. Karabudak, "Comparing routine neurorehabilitation program with trunk exercises based on Bobath concept in multiple sclerosis: pilot study," The Journal of Rehabilitation Research and Development, vol. 50, no. 1, pp. 133-140, 2013.

[36] S.-H. Yu and S.-D. Park, "The effects of core stability strength exercise on muscle activity and trunk impairment scale in stroke patients," Journal of Exercise Rehabilitation, vol. 9, no. 3, pp. 362-367, 2013.

[37] T. O. Cheng, "Tai Chi: the Chinese ancient wisdom of an ideal exercise for cardiac patients," International Journal of Cardiology, vol. 117, no. 3, pp. 293-295, 2007.

[38] C. Wang, C. H. Schmid, R. Rones et al., "A randomized trial of Tai Chi for fibromyalgia," New England Journal of Medicine, vol. 363, no. 23, pp. 2265-2267, 2010.

[39] Z. D. Cai, S. J. Lou, A. G. Chen et al., "Expert consensus on the dose-effect relationship of physical exercise delaying cognitive decline in the elderly," Journal of Shanghai University of Sport, vol. 45, no. 1, pp. 51-65+77, 2021.

[40] G. Xie, T. Rao, L. Lin et al., "Effects of Tai Chi Yunshou exercise on community-based stroke patients: a cluster randomized controlled trial," European Review of Aging and Physical Activity, vol. 15, p. 17, 2018.

[41] S. Pan, D. Kairy, H. Corriveau, and M. Tousignant, "Adapting Tai Chi for upper limb rehabilitation post stroke: a feasibility study," Medicines, vol. 4, no. 4, pp. 72-85, 2017.

[42] I. Hwang, R. Song, S. Ahn, M.-A. Lee, P. M. Wayne, and M. K. Sohn, "Exploring the adaptability of tai chi to stroke rehabilitation," Rehabilitation Nursing, vol. 44, no. 4, pp. 221-229, 2019.
[43] B. L. Chen, J. B. Guo, M. S. Liu et al., "Effect of traditional Chinese exercise on gait and balance for stroke: a systematic review and meta-analysis," PloS One, vol. 10, no. 8, p. e0135932, 2015.

[44] H. Li, H. H. Yao, and L.-H. Liu, "Effects of muscle strengthening exercise on gait of stroke patients and the relationship between the evaluation of gait analysis and functional assessment," Chinese Journal of Physical Medicine and Rehabilitation, vol. 25, no. 1, pp. 36-38, 2003.

[45] L. P. Zhou, W. P. Li, and D. W. Mao, "Effect of Tai Chi exercise on elderly people's physiological characteristics in biomechanics," Shandong Sports Science and Technology, vol. 31, no. 2, pp. 7-11, 2009.

[46] X. B. Wang, M. J. Hou, J. Tao et al., "The effect of Tai Chi Yunshou on gait of community-based hemiplegic patients after stroke," Chinese Journal of Rehabilitation Medicine, vol. 31, no. 12, pp. 1328-1333, 2016.

[47] M. G. Yang, H. Zhong, M. J. Hou et al., “Three-dimensional gait analysis of Taiji Yunshou in stroke patients with hemiplegia," Asia-pacific Traditional Medicine, vol. 14, no. 4, pp. 139-141, 2018.

[48] J. Hart, H. Kanner, R. Gilboa-Mayo et al., "Tai Chi Chuan practice in community-dwelling persons after stroke," International Journal of Rehabilitation Research, vol. 4, no. 27, pp. 303-304, 2004.

[49] D. H. Yu, S. Wang, H. X. Yang et al., "Effects of 24-week Tai Chi exercise on the static postural balance of the elder persons," Chinese Journal of Sports Medicine, vol. 30, no. 12, pp. 1115-1119, 2011.

[50] Y. Zhao, D. H. Yu, and H. X. Yang, "Influence of Taijiquan exercise in different years on the static balance ability of middle-aged and elderly women," Chinese Journal of Sports Medicine, vol. 33, no. 10, pp. 1015-1018, 2004. 